\title{
Consolidation of Fear Extinction Requires Protein Synthesis in the Medial Prefrontal Cortex
}

\author{
Edwin Santini, ${ }^{1}$ Hong Ge, ${ }^{2}$ Keqin Ren, ${ }^{2}$ Sandra Peña de Ortiz, ${ }^{2}$ and Gregory J. Quirk ${ }^{1}$ \\ ${ }^{1}$ Department of Physiology, Ponce School of Medicine, Ponce, Puerto Rico 00732, and 2Department of Biology, University of Puerto Rico at Rio Piedras, San \\ Juan, Puerto Rico 00931
}

\begin{abstract}
Extinction of conditioned fear is thought to form a long-term memory of safety, but the neural mechanisms are poorly understood. Consolidation of extinction learning in other paradigms requires protein synthesis, but the involvement of protein synthesis in extinction of conditioned fear remains unclear. Here, we show that rats infused intraventricularly with the protein synthesis inhibitor anisomycin extinguished normally within a session but were unable to recall extinction the following day. Anisomycin-treated rats showed no savings in the rate of re-learning of extinction, consistent with amnesia for extinction training. The identical effect was observed when anisomycin was microinfused into the medial prefrontal cortex ( $\mathrm{mPFC}$ ) but not the insular cortex. Furthermore, we observed that extinction training increased c-Fos levels in the mPFC but not in the insular cortex, consistent with extinction-induced gene expression in the mPFC. These findings extend previous lesion and unit-recording data by demonstrating that the $\mathrm{MPFC}$ is a critical storage site for extinction memory, rather than simply a pathway for expression of extinction. Understanding consolidation of fear extinction could lead to new treatments for anxiety disorders in which fear extinction is thought to be compromised.
\end{abstract}

Key words: fear conditioning; reconsolidation; c-Fos; amygdala; memory; infralimbic

\section{Introduction}

It is now well established that memory consolidation requires gene expression and protein synthesis (Silva et al., 1998; Kandel, 2001; Pena de Ortiz and Arshavsky, 2001). This has been elegantly demonstrated in studies of cued fear conditioning in which a tone or light is paired with a mild footshock (Ressler et al., 2002; Lamprecht and LeDoux, 2004). Long-term memory for the toneshock association can be blocked by infusing the protein synthesis inhibitor anisomycin (ANISO) into the basolateral amygdala (BLA) just before training (Schafe and LeDoux, 2000; Maren et al., 2003). Moreover, fear conditioning induces the expression of immediate-early genes in the BLA that are thought to trigger secondary transcriptional cascades that stabilize early synaptic changes (Rosen et al., 1998; Ressler et al., 2002).

Although the molecular mechanisms of fear acquisition have been studied extensively, less is known about fear extinction, in which unreinforced tones cause fear responses to decrease. Behavioral studies suggest that extinction does not erase conditioning but forms a separate memory that inhibits conditioned responding (Bouton and King, 1983; Rescorla, 2001). Memory for fear extinction can last 10 d or longer (Herry and Garcia, 2002; Quirk, 2002), suggesting the involvement of gene expression and protein synthesis. Extinction in other paradigms requires protein

Received March 4, 2004; revised May 11, 2004; accepted May 12, 2004.

This work was supported by National Institutes of Health Grants F31-MH066575 (E.S.), R01-MH058883 and S06-GM08239 (G.J.Q.), and P20-RR015565 (S.P.d.O.). We thank Marian Sepulveda for assistance with the behavioral studies and Drs. Ted Abel, Mohammed Milad, Karim Nader, and Denis Paré for comments on this manuscript.

Correspondence should be addressed to Dr. Gregory J. Quirk, Department of Physiology, Ponce School of Medicine, P.0. Box 7004, Ponce, Puerto Rico 00732-7004. E-mail: gjquirk@yahoo.com.

DOI:10.1523/JNEUROSCI.0786-04.2004

Copyright $\odot 2004$ Society for Neuroscience $\quad$ 0270-6474/04/245704-07\$15.00/0 synthesis (Berman and Dudai, 2001; Vianna et al., 2001; Pedreira and Maldonado, 2003), however, the extent to which extinction of fear depends on protein synthesis is unclear (Lattal and Abel, 2001; Fischer et al., 2004).

If memory for fear extinction depends on protein synthesis, which structure(s) consolidates and stores extinction memory? One candidate structure is the medial prefrontal cortex (mPFC). Rats with lesions of the $\mathrm{mPFC}$ have difficulty recalling extinction learned the previous day (Morgan et al., 1993; Quirk et al., 2000; but see Gewirtz et al., 1997). Consistent with this, recall of extinction is correlated with plasticity in mPFC single units (Milad and Quirk, 2002), mPFC-evoked potentials (Herry and Garcia, 2002), and mPFC glucose utilization (Barrett et al., 2003). These findings do not tell us, however, whether the $\mathrm{mPFC}$ is a site of storage of extinction memory or simply a route for expression of extinction stored elsewhere. To address this issue, we first infused ANISO intraventricularly to determine whether consolidation of fear extinction requires protein synthesis anywhere in the brain. We next microinfused ANISO into either the mPFC or the insular cortex, a structure implicated in extinction of conditioned taste aversion. Finally, we examined the effect of extinction training on the expression of the immediate-early gene c-fos in the $\mathrm{mPFC}$ and insular cortex. A preliminary report of these findings has appeared (Santini et al., 2003).

\section{Materials and Methods}

Subjects. The procedures were approved by the Institutional Animal Care and Use Committee of the Ponce School of Medicine in compliance with National Institutes of Health (NIH) guidelines for the care and use of laboratory animals (Publication number DHHS NIH 86-23). Male Sprague Dawley rats weighing 270-300 gm were transported from the 
A

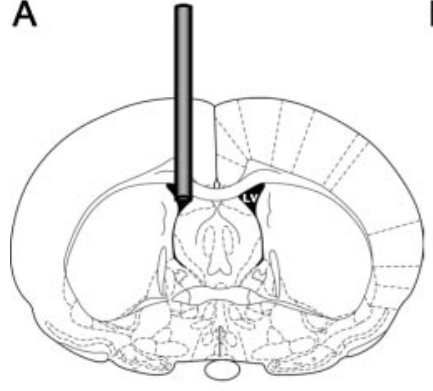

B

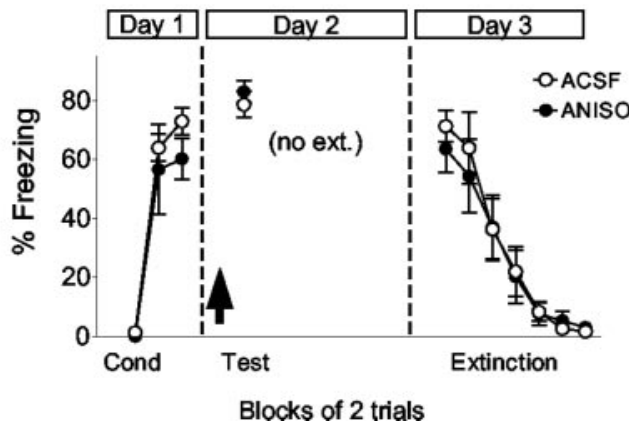

C

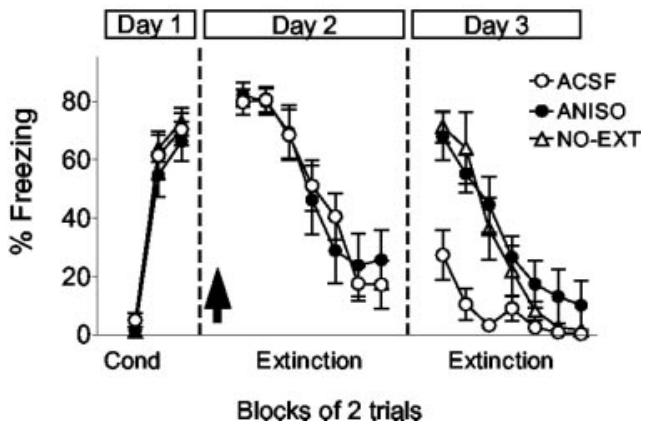

Figure 1. Infusing the protein synthesis inhibitor ANISO into the lateral ventricle blocked retention, but not acquisition, of fear extinction. $A$, Drugs were infused through a cannula chronically implanted into the left lateral ventricle (LV). $B$, Freezing to the tone shown in blocks of two trials across all phases of the experiment (trial 7 of conditioning and trial 15 of extinction not shown). 0 n day 1, rats were fear conditioned (Cond). On day 2, rats were infused intraventricularly with $300 \mu$ g of ANISO $(n=6)$ or vehicle (ACSF; $n=6$ ), followed by two extinction tones (Test). 0 n day 3 , both groups showed equivalently high freezing, indicating that ventricular ANISO does not interfere with reconsolidation of conditioning memory. no-ext, No extinction. $C$, The experiment was repeated with separate rats given 15 extinction tones. Rats infused with ANISO $(n=9)$ showed normal within-session extinction compared with ACSF controls ( $n=9$ ) but were unable to recall extinction on day 3 (high freezing). ANISO rats showed no savings in their rate of relearning compared with NO-EXT controls $(n=6)$, suggesting amnesia for original extinction training. In this and all subsequent figures, the arrows indicate infusion and the error bars indicate SEM. Histology drawings in this and subsequent figures were adapted from Paxinos and Watson (1998).

Ponce School of Medicine colony to a satellite facility where they were individually housed in transparent polyethylene cages inside a negativepressure Biobubble (Colorado Clean Room, Ft. Collins, CO). Rats were maintained on a $12 \mathrm{hr}$ light/dark schedule with ad libitum access to water. Food was restricted to $10-15$ gm of standard laboratory rat chow per day until rats reached $85 \%$ of their original weight. They were then trained to press a bar for food on a variable interval schedule of reinforcement (VI-60), in a standard operant chamber (Coulborn Instruments, Allentown, PA). This was done to maintain a constant level of activity against which freezing can be reliably measured (Quirk et al., 2000).

Surgery. After bar-press training, rats were anesthetized with ketamine ( $80-90 \mathrm{mg} / \mathrm{kg}$, i.p.)-xylazine (5-10 mg/kg, i.p.), after pretreatment with atropine $(0.24 \mathrm{mg} / \mathrm{kg}$, i.p.). Rats were implanted with a 26 gauge stainless steel guide cannula in one of three sites, according to a stereotaxic atlas (Paxinos and Watson, 1998): left lateral ventricle [anteroposterior (AP), $-0.4 \mathrm{~mm}$; mediolateral (ML), $+1.3 \mathrm{~mm}$; dorsoventral (DV), $-4.2 \mathrm{~mm}$ from the skull], ventral $\mathrm{mPFC}(\mathrm{AP},+2.9 \mathrm{~mm}$; $\mathrm{ML},-1.0 \mathrm{~mm}$; DV,-4.1 $\mathrm{mm}$ from the skull, angled $11^{\circ}$ toward the midline in the coronal plane), or insular cortex (AP, $+1.2 \mathrm{~mm}$; ML, $\pm 5.5 \mathrm{~mm}$; DV,$-5.5 \mathrm{~mm}$ from the skull). A 33 gauge dummy cannula was inserted into the guide cannula to prevent clogging. Guide cannulas were cemented to the skull with dental acrylic (Grip Cement), and the incision was sutured. After surgery, a triple antibiotic was applied and an analgesic was given (Buprenorphine; $0.67 \mathrm{ml} / \mathrm{kg}$, i.m.). Rats were allowed $7 \mathrm{~d}$ to recover before experimental procedures.

Fear conditioning. Rats were fear conditioned and extinguished in an operant chamber while pressing for food. The chamber was $25 \times 29 \times 28$ $\mathrm{cm}$ with aluminum and Plexiglas walls (Coulborn Instruments). The floor consisted of stainless steel bars that could be electrified to deliver a mild shock. A response bar was positioned $6.5 \mathrm{~cm}$ above the floor, a speaker was mounted on the outside wall opposite the bar, and illumination was provided by a single overhead light. The chamber was situated inside a sound-attenuating box (Med Associates, Burlington, VT) with a ventilating fan, which produced an ambient noise level of $60 \mathrm{~dB}$. The conditioned stimulus was a $4 \mathrm{kHz}$ sine wave with a duration of $30 \mathrm{sec}$ and an intensity of $80 \mathrm{~dB}$. The unconditioned stimulus was a $0.5 \mathrm{~mA}$ scrambled footshock, $0.5 \mathrm{sec}$ in duration, which co-terminated with the tone during the conditioning phase. Throughout the experiment, food was continuously available on a VI-60 schedule. Between sessions, floor trays and shock bars were cleaned with soapy water and the chamber walls were wiped with a damp cloth. Behavior was recorded with digital video cameras (Micro Video Products, Ontario, Canada).

Anisomycin experiments. On day 1, rats received five habituation trials (tone alone), followed by seven conditioning trials [tone paired with shock; intertrial interval (ITI), 4 min). Afterward, rats were matched for acquired freezing levels, and assigned to one of three experimental groups: ANISO, artificial cerebrospinal fluid (ACSF) vehicle control, or no-extinction (NO-EXT) controls. On day 2, all animals were infused with either ACSF or ANISO into the left lateral ventricle $(300 \mu \mathrm{g}$ in $5 \mu \mathrm{l})$ (Schafe et al., 1999), mPFC (50 $\mu \mathrm{g}$ in $0.5 \mu \mathrm{l}$ in a single midline injection), or insular cortex (100 $\mu \mathrm{g} ; 0.5 \mu \mathrm{l}$ per side), as described previously (Berman and Dudai, 2001). The infusion rate was $0.1 \mu \mathrm{l} / \mathrm{min}$ in all experiments. After the infusion, a delay of $10 \mathrm{~min}$ (for ventricular infusions) or $20 \mathrm{~min}$ (for mPFC and insular infusions) was interposed before extinction training. Rats received 15 extinction tones with an ITI of 2 min, resulting in a 50 min session. The NO-EXT controls were infused with ACSF, given only two extinction trials, and then returned to their home cages. On day 3 , all groups received 15 additional extinction trials to test for recall of extinction and assess the rate of re-learning of extinction.

Data analysis. The percentage of time spent freezing (Blanchard and Blanchard, 1972) was used as a measure of conditioned fear. Freezing is the cessation of all movements, except respiration. The total time spent freezing during the $30 \mathrm{sec}$ tone was scored from videotape with a digital stopwatch by observers blinded with respect to the experimental group. Percentage of recovery of freezing was calculated by dividing the average freezing in extinction trials $1-2$ (day 3 ) by the average in conditioning trials 6-7 (day 1). Freezing and recovery values were analyzed with either Student's $t$ test or one-way ANOVA (STATISTICA; Statsoft, Tulsa, OK). After a significant main effect, post hoc tests were performed with the Scheffé method.

Histology. At the conclusion of the experiments, rats were microinfused with an equivalent volume of methylene blue $(0.5 \mu \mathrm{l}$ of $0.5 \%)$ to estimate the spread of ANISO. The borders of the dye spread were drawn for each rat. Afterward, the rats received an overdose of pentobarbital $(150 \mathrm{mg} / \mathrm{kg})$ and were perfused transcardially with $0.9 \%$ saline, followed by buffered formalin. Brains were removed and placed in $10 \%$ buffered formalin with $30 \%$ sucrose. Frozen sections ( $40 \mu \mathrm{m}$ thickness) were stained for Nissl bodies, and the cannula tips were drawn.

c-Fos experiments. There were five treatment groups. (1) Extinction rats (EXT) received five habituation trials immediately, followed by seven conditioning trials (ITI, $4 \mathrm{~min}$ ). After $2 \mathrm{hr}$ in the home cage, they were returned to the conditioning chamber for 20 extinction trials (ITI, 4 min). (2) NO-EXT rats were conditioned as above but were given only two extinction trials and immediately returned to their home cages. (3) Unpaired rats received tones and shocks in an unpaired manner during the conditioning phase and were returned to their home cages for the duration of the experiment. (4) Tone-alone rats received a full set of habituation, conditioning, and extinction tones but were never shocked. (5) No-tone/shock rats received neither tones nor shocks but simply pressed for food in the conditioning chamber for the same amount of time as the EXT group. After training, all groups received two test tones (30 sec each; ITI, $4 \mathrm{~min}$ ) and then were etherized and decapitated within 
A

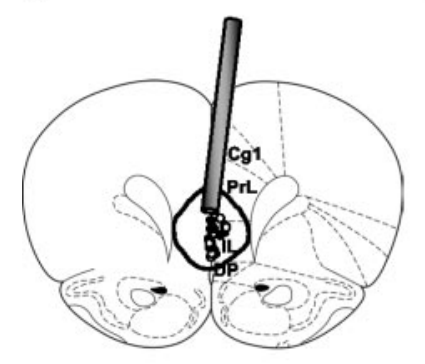

B

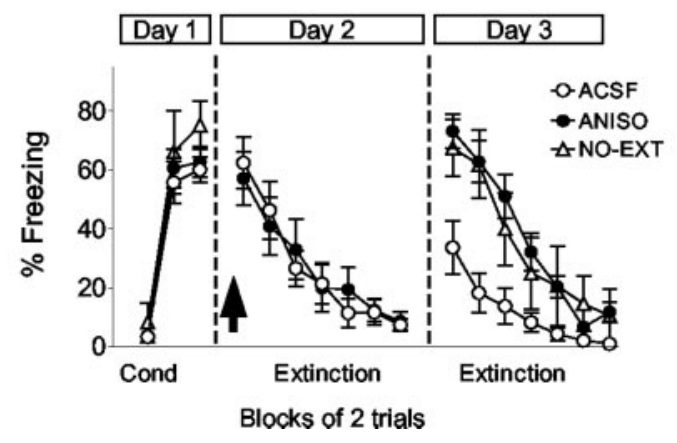

C

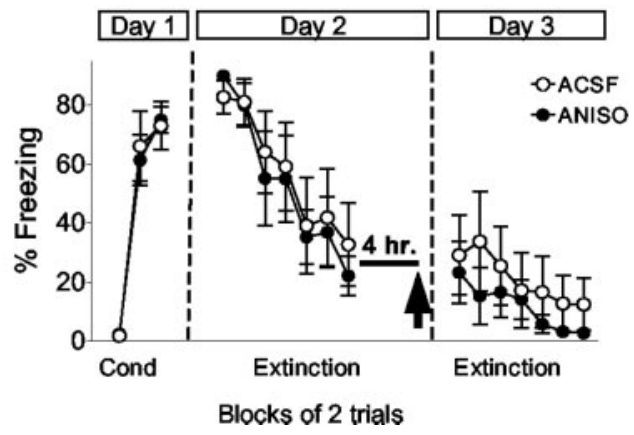

Figure 2. Infusing ANISO into the mPFC blocked retention, but not acquisition, of fear extinction. $A$, Location of cannula tips in the mPFC for the ANISO (O) and ACSF ( $\bigcirc$ ) groups. The extent of dye spread, averaged across all rats in the ANISO group, is indicated by the thick line. IL, Infralimbic area; PrL, prelimbic area; Cg1, cingulate cortex; DP, dorsal peduncular area. $B$, Freezing to the tone. Just before extinction on day 2, rats were infused with $50 \mu \mathrm{g}$ of ANISO $(n=12$ ) or vehicle (ACSF, $n=12$; N0-EXT, $n=6$ ). Rats infused with ANISO into the mPFC showed normal within-session extinction but could not recall extinction on day 3 . As with ventricular infusions, ANISO-infused rats showed no savings in their rate of re-learning of extinction training. $C$, Infusing ANISO into the $\mathrm{mPFC} 4 \mathrm{hr}$ after extinction training had no effect (ANISO, $n=6 ; \mathrm{ACSF}, n=6$ ). Cond, Conditioning.

5 min of the last test tone. This occurred 30 min after the end of the extinction session and $4 \mathrm{hr}$ after the end of conditioning. Brains were frozen on dry ice and maintained at $-80^{\circ} \mathrm{C}$. For the Western blot experiment, EXT and NO-EXT animals were treated as above, except that the NO-EXT rats remained in the chamber for the duration of the extinction session, to control for context exposure. After the test tones, brains were removed immediately and chilled on dry ice. Coronal sections containing the $\mathrm{mPFC}$ were obtained using a Brain Matrix (Ted Pella, Redding, $\mathrm{CA})$. Tissue punches ( $3 \mathrm{~mm}$ thick) were obtained bilaterally from the $\mathrm{mPFC}$ and insular cortex under a dissecting microscope. Samples were stored at $-80^{\circ} \mathrm{C}$ until nuclear protein extraction (see below).

Immunohistochemistry. Frozen coronal sections were cut from unfixed tissue $\left(25 \mu \mathrm{m}\right.$ thick) in a cryostat at $-20^{\circ} \mathrm{C}$. Sections were pretreated as described previously (Ge et al., 2003). The primary anti-rabbit c-Fos polyclonal antibody (Santa Cruz Biotechnology, Santa Cruz, CA) was used at a 1:100 dilution, and the goat anti-rabbit biotinylated secondary antibody was diluted at 9:1000. Detection was done with $A B C$ peroxidase reagent (avidin-biotin peroxidase complex; Pierce, Rockford, IL) and DAB. DAB-oxidized brown precipitates were visualized at $10 \times$ and captured with a digital camera. Binding specificity of the antibody was confirmed with immunoabsorption with a Fos peptide. c-Fosimmunoreactive nuclei in the dorsal third, medial third, and ventral third of the mPFC were counted with the Image/J software (Scion, Frederick, MD). The number of positive nuclei per square millimeter was compared across treatment groups with one-way ANOVA and Fisher LSD post hoc tests.

Nuclear protein extraction and Western blotting. Tissue from the mPFC and insular cortex was collected in pools of six rats per condition, yielding two pools for the EXT condition and two pools for the NO-EXT condition. From this, a total of four Western blot experiments (each containing both structures and both conditions) were run. The procedures for nuclear protein extraction (performed at $4^{\circ} \mathrm{C}$ ) were modified from Best et al. (1999). The nuclear fraction was precipitated by centrifugation for $10 \mathrm{~min}$ at 14,000 rpm. The pellet was resuspended in $300 \mu \mathrm{l}$ of ice-cold extraction buffer (10 mM HEPES-KOH, pH 7.9, 20\% glycerol, $50 \mathrm{~mm}$ $\mathrm{NaCl}, 5 \mathrm{~mm} \mathrm{MgCl}, 0.2 \mathrm{~mm}$ EDTA, 5 mм DTT, $1 \mathrm{~mm}$ PMSF, $2 \mu \mathrm{g} / \mathrm{ml}$ aprotinin, and $2 \mu \mathrm{g} / \mathrm{ml}$ leupeptin), incubated on ice for $30 \mathrm{~min}$, and then centrifuged at $14,000 \mathrm{rpm}$ for $20 \mathrm{~min}$. The supernatant was collected, and the protein concentration was determined by the Bradford method. The protein samples were stored at $-80^{\circ} \mathrm{C}$ until used. Western blotting was performed as described previously (Ge et al., 2003). The blotted membrane was incubated first with 1:1000 c-Fos antibody (Santa Cruz Biotechnology) and subsequently with 1:1000 biotinylated secondary antirabbit antibody (Amersham Biosciences, Piscataway, NJ). Antibody binding specificity was confirmed by immunoabsorption with a c-Fos peptide. The ECL + system (Amersham Biosciences) was used for immune detection. Membranes were then stripped of antibodies and reprobed for actin as described previously (Ge et al., 2003). Films were scanned and analyzed in a densitometer (Molecular Dynamics, Sunnyvale, CA; and Amersham Biosciences). Data normalization was done by dividing the mean c-Fos optical densities per condition by the corresponding actin optical densities. c-Fos/actin ratios were compared with a two-tailed unpaired $t$ test.

\section{Results}

\section{Memory for fear extinction requires protein synthesis}

To determine whether memory for extinction of cued fear conditioning depends on protein synthesis anywhere in the brain, ANISO was infused into the lateral ventricle (Fig. $1 A$ ). We initially investigated whether this might interfere with reconsolidation of conditioning memory (Nader et al., 2000; Eisenberg et al., 2003), which could confound our analysis of extinction retention. On day 1, rats were conditioned with seven tone-shock pairings. On day 2, they received intraventricular ANISO or ACSF, followed 20 min later by two extinction tones, which did not cause significant extinction in this task. ANISO did not impair recall of conditioning the following day (Fig. $1 B$ ). The ANISO and ACSF groups froze $64 \pm 7.9$ and $71 \pm 5.4 \%$, respectively, which were not significantly different $\left(t_{9}=0.77 ; p=0.46\right)$. Thus, in agreement with a prior report (Debiec et al., 2002), ventricular ANISO did not interfere with reconsolidation of fear conditioning.

We repeated this experiment in separate rats, giving 15 extinction tones instead of two (Fig. 1C). Intraventricular ANISO did not impair the rats' ability to extinguish fear to the tone within the training session. The following day, however, ANISO-treated rats behaved as if they never received extinction, showing high freezing that was equivalent to a control group that was not ex-
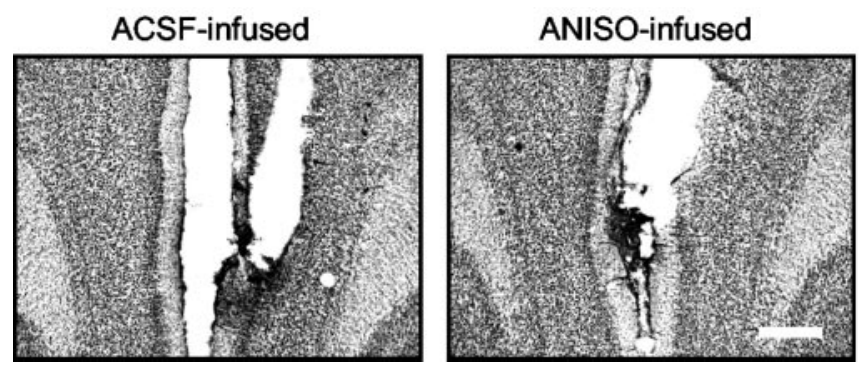

Figure 3. ANISO did not lesion the mPFC. Representative photomicrographs show mPFC tissue from rats infused with ACSF (left) or ANISO (right). There was no evidence of increased cell loss or gliosis in the ANISO animals. Scale bar, $0.5 \mathrm{~mm}$. 
A

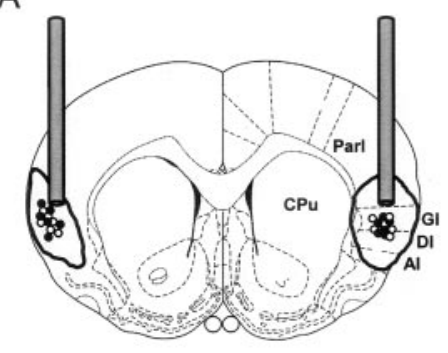

B

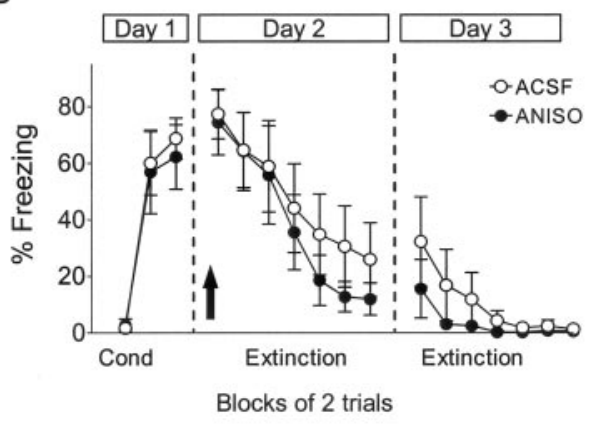

C

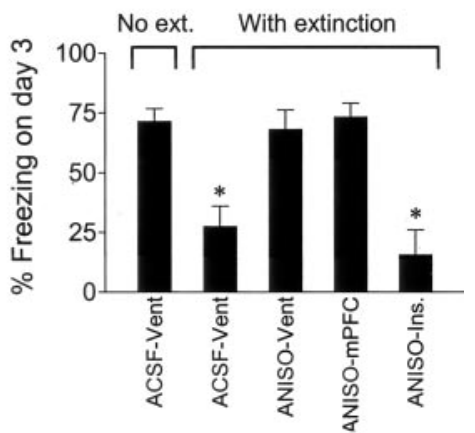

Figure 4. Infusing ANISO into the insular cortex had no effect on acquisition or retention of extinction. A, Location of cannula tips in the insular cortex for the ANISO (O) and ACSF $(\bigcirc)$ groups and approximate spread of an equivalent volume of dye. Par1, Parietal cortex area 1; Gl, granular insular cortex; DI, dysgranular insular cortex; Al, agranular insular cortex; $\mathrm{CPu}$, caudate-putamen. $B$, Freezing to the tone. ANISO infused before extinction training did not impair acquisition or retention of extinction (ANISO, $n=6 ; A C S F, n=6$ ). Cond, Conditioning. C, Histogram summarizing the ANISO experiments. Vent, Ventricular infusion; Ins., insular cortex. ANOVA showed a main effect of group $\left(F_{(3,37)}=11.06 ; p<0.001\right)$. Post hoc comparisons showed that only the ACSF-extinction and ANISO-insular groups significantly differed from NO-EXT controls (both ${ }^{*} p<0.05$ ), indicating that ANISO blocked extinction memory when infused into the lateral ventricle or $\mathrm{mPFC}$ but not the insular cortex.

tinguished (NO-EXT group). Average freezing to the first two tones on day 3 was 68,27 , and $71 \%$ in the ANISO, ACSF, and NO-EXT groups, respectively. Expressed as a percentage of acquired freezing, the ANISO, ACSF, and NO-EXT groups recovered 98,39 , and $102 \%$, respectively. ANOVA indicated a main effect of group $\left(F_{(2,20)}=8.765 ; p<0.001\right)$, with ANISO rats showing significantly higher freezing than ACSF rats $(p<0.01)$ and equivalent freezing to NO-EXT controls $(p=0.8)$. Furthermore, ANISO rats showed no savings in their rate of re-learning of extinction compared with NO-EXT controls (Fig. 1C), consistent with amnesia for extinction training, although a profound deficit in retrieval cannot be ruled out. Thus, ANISO given before extinction training blocked long-term retention of extinction, without impairing its acquisition.

The high level of freezing in the ANISO group could not be attributed to reduced drive to press for food, because the rate of spontaneous bar-pressing at the start day 3 did not differ significantly between groups (ACSF, 30 presses/min; ANISO, 25 presses $/ \mathrm{min} ; t_{16}=0.83 ; p=0.41$ ).

\section{ANISO does not induce state-dependent learning}

One possible explanation of our findings is that ANISO induced a behavioral state during extinction training, which would be required at test for recall of extinction (Bouton et al., 1990). In the above experiments, rats were trained under ANISO and tested drug free. To test for a possible state-dependent effect, we repeated the above experiment, except that one group received ANISO both during extinction training and test (ANISO-ANISO group), whereas another group received ANISO during training, followed by ACSF at test (ANISO-ACSF group). Contrary to predictions of state-dependent learning, ANISO given at test failed to trigger recall of extinction. At test, the ANISO-ANISO group froze $69 \%( \pm 6.8)$ compared with $57 \%( \pm 15.6)$ in the ANISOACSF group. The corresponding freezing recovery values were 99 and $100 \%$ for the ANISO-ACSF and ANISO-ANISO groups, respectively, which were not significantly different $\left(t_{10}\right.$ $=0.0325 ; p=0.97$ ). Thus, as observed previously (Patterson et al., 1989), intraventricular ANISO does not induce statedependent learning.
Memory for fear extinction requires protein synthesis in the mPFC but not the insular cortex

To determine the site of extinction-dependent protein synthesis, we microinfused ANISO directly into the mPFC or insular cortex shortly before extinction training. Similar to ventricular infusions, rats infused bilaterally with ANISO into the mPFC extinguished normally but were unable to recall extinction the following day (Fig. $2 A, B$ ). The percentage of recovery of freezing on day 3 was 111,52 , and $95 \%$ in the ANISO, ACSF, and NO-EXT groups, respectively. One-way ANOVA of recovery values showed a main effect of group $\left(F_{(2,27)}=5.34 ; p<0.01\right)$, with post hoc tests confirming that ANISO rats showed significantly higher freezing than ACSF controls $(p<0.01)$ and equivalent freezing to NO-EXT controls. The rate of spontaneous bar-pressing was not affected by ANISO (ACSF, 29 presses/min; ANISO, 30 presses $\left./ \mathrm{min} ; t_{22}=0.32 ; p=0.74\right)$. Similar to the intraventricular infusions, ANISO-treated rats showed no savings in their rate of re-learning of extinction. Infusion of ANISO $4 \mathrm{hr}$ after extinction had no effect (Fig. 2C), indicating that extinction-related protein synthesis is time limited. The lack of effect at $4 \mathrm{hr}$ also suggests that ANISO did not damage the mPFC. In further support of this, histological analysis showed no evidence of increased gliosis or cell loss in ANISO-treated rats (Fig. 3).

In contrast to the MPFC, bilateral infusions of ANISO into the insular cortex had no effect (Fig. 4B). Recovery of freezing on day 3 in the ANISO group (16 $\pm 10.3 \%)$ was not significantly different from the ACSF group $\left(32 \pm 15.8 \% ; t_{10}=1.07 ; p=0.31\right)$. The results of all experiments are summarized in Figure $4 C$, which shows that extinction memory was blocked by ANISO infused into the lateral ventricle or mPFC but not the insular cortex.

\section{Extinction training induces c-Fos in the MPFC but not the insular cortex}

Our findings suggest that extinction triggers synthesis of proteins in the $\mathrm{mPFC}$ that are essential for long-term memory storage. To further investigate this possibility, we used immunohistochemical techniques to measure c-Fos protein levels in the mPFC. c-Fos is the product of the immediate-early gene c-fos and functions as a transcription factor in various learning paradigms (for review, see Kaczmarek, 2002), including acquisition of fear conditioning (Rosen et al., 1998; Hall et al., 2001). 
c-Fos levels were assessed in two conditioned groups (EXT and NO-EXT) and three unconditioned control groups (unpaired, tone-only, and no-tone/shock; see Materials and Methods). The EXT and NO-EXT groups acquired equivalent levels of conditioned freezing to the tone (57 and 55\%, respectively). Extinction training reduced freezing in the EXT group to $12.5 \%$, whereas the NO-EXT group remained at $63 \%$. When tested $20 \mathrm{~min}$ after extinction, freezing levels were unchanged (EXT, 9\%; NO-EXT, 57\%). Freezing in the unconditioned controls was $<4 \%$ in all groups (Fig. 5A). One-way ANOVA revealed a main effect of group $\left(F_{(4,65)}=\right.$ 33.0 ; $p<0.001$ ), with post hoc tests confirming that the NO-EXT group showed significantly higher freezing than all other groups (all $p<0.001$ ).

Rats were killed immediately after the test tones. This occurred $4 \mathrm{hr}$ after the end of conditioning and $30 \mathrm{~min}$ after the end of extinction. Given that the latency for c-Fos induction is $30-60 \mathrm{~min}$ (Kaczmarek, 2002), we were in a position to detect c-Fos expression that might be initiated during extinction training. In fact, the density of c-Fos-labeled cells in the EXT group was significantly greater than controls in all three mPFC subregions examined (Fig. $5 B, C)$. ANOVA showed a main effect of group for each area (dorsal mPFC: $F_{(4,65)}$ $=6.45, p<0.001$; middle mPFC: $F_{(4,65)}=$ 3.63, $p<0.01$; ventral mPFC: $F_{(4,65)}=$ 3.75; $p<0.01)$. Post hoc tests confirmed that the EXT group showed a significantly higher density of c-Fos-labeled cells than all control groups in the dorsal mPFC (all $p<0.01$ ), medial mPFC (all $p<0.05$ ), and ventral mPFC (all $p<0.05)$. The low levels of c-Fos in the control groups allowed us to rule out factors such as acquisition of conditioning, recall of conditioning, footshock stimulation, or tone stimulation as causes of increased c-Fos at this time point. Thus, we concluded that the increased c-Fos signal in the EXT group was attributable to extinction training per se.

To confirm these findings, we used Western blots to measure c-Fos protein in separate EXT and NO-EXT groups, trained as above. Immediately after the test tones, the entire mPFC and insular cortex were dissected and homogenized for protein extraction. In both areas, Western blots revealed a clear band at 62 $\mathrm{kDa}$, corresponding to c-Fos protein (Fig. 6). In the mPFC, the EXT group showed significantly higher levels of c-Fos (normalized to actin) compared with the NO-EXT controls $\left(t_{6}=2.95\right.$; $p<0.05$ ), confirming our immunocytochemical results. In contrast, the insular cortex showed equivalent c-Fos levels in both groups $\left(t_{6}=0.84 ; p=0.43\right)$.

\section{Discussion}

We used ANISO and c-Fos immunolabeling to investigate the molecular mechanisms of consolidation of fear extinction. Our results can be summarized as follows: (1) consolidation of fear
B
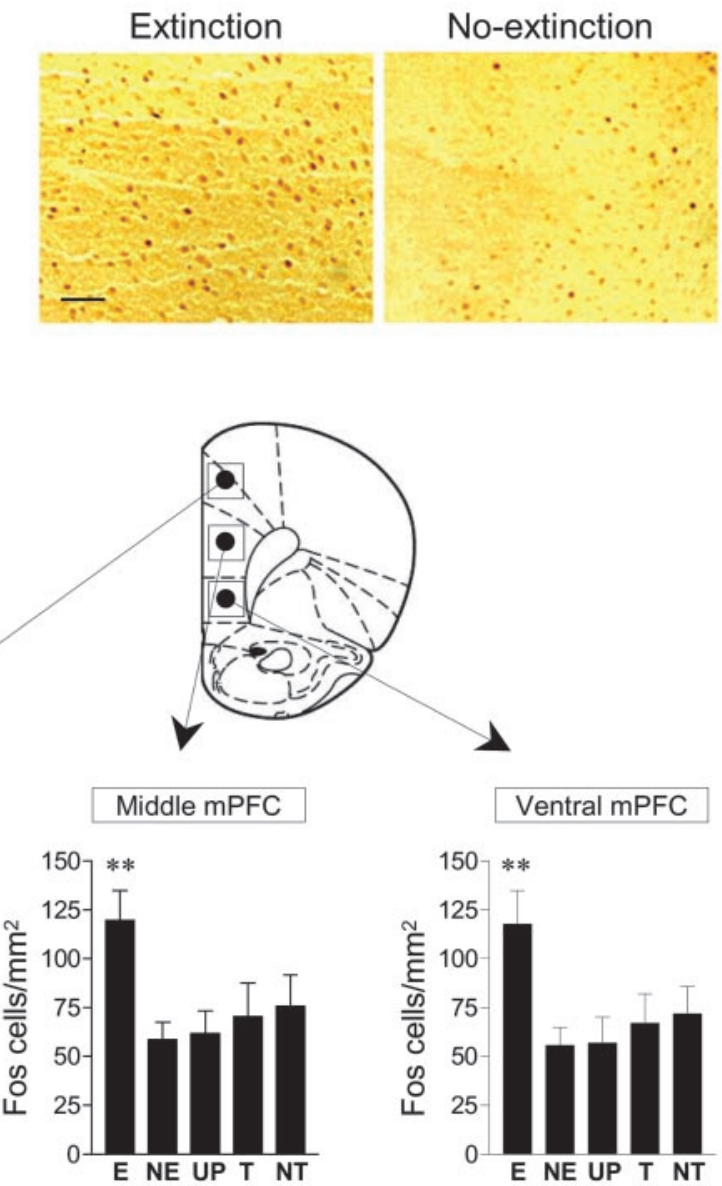

Figure 5. Extinction increased the density of $c-F o s-l a b e l e d$ cells in the $\mathrm{MPFC}$. $A$, Freezing to the test tones for rats that received extinction ( $\mathrm{E} ; n=17)$, no-extinction (NE; $n=17)$, unpaired tones and shocks (UP; $n=12)$, tones only (T; $n=13)$, or no-tones ocks (NT; $n=11)$. Freezing in the extinction group was significantly lower than N0-EXT controls $\left({ }^{* * *} p<0.001\right)$ and was no NO-EXT brains. Scale bar, $0.1 \mathrm{~mm}$. C, Histograms showing the average density of c-Fos-labeled nuclei across treatment groups, in the dorsal, middle, and ventral subdivisions of the $\mathrm{mPFC}$, corresponding to the cingulate, prelimbic, and infralimbic cortices, respectively. The extinction group showed significantly more c-Fos-labeled cells than controls, in all three subregions $\left({ }^{* * *} p<\right.$ $0.001 ;{ }^{* *} p<0.01$; main effect; one-way ANOVA).

extinction requires protein synthesis; (2) the $\mathrm{MPFC}$, but not the insular cortex, is a critical site of extinction-induced protein synthesis; and (3) extinction training increases the product of the immediate-early gene c-fos in the mPFC, but not the insular cortex. This is the first demonstration that long-term memory for fear extinction requires protein synthesis in the mPFC, suggesting that the mPFC is a site of consolidation and storage in this paradigm.

The observation that extinction of cued fear conditioning requires protein synthesis agrees with recent studies of extinction of conditioned taste aversion (Berman and Dudai, 2001; Eisenberg et al., 2003) and inhibitory avoidance (Vianna et al., 2001, 2003). It disagrees, however, with a previous report in which extinction of contextual fear conditioning and water maze training were unaffected by ANISO administered systemically (Lattal and Abel, 2001). Whether this difference is caused by the route of drug administration or reflects a fundamental difference between extinction of tone versus context conditioning remains unclear. It is worth noting that lesions of the mPFC, which are so deleterious for extinction of tone fear (Morgan et al., 1993; Quirk et al., 
A

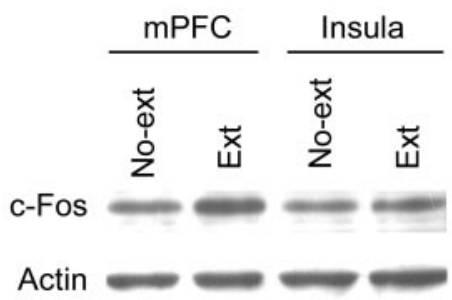

B

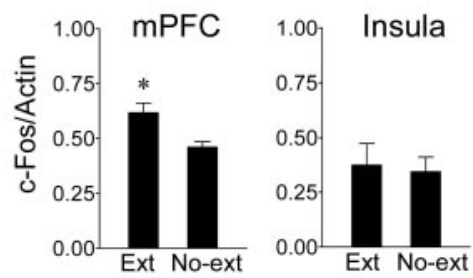

Figure 6. Extinction increased c-Fos protein levels in the mPFC but not insular cortex. A, Western blots showing c-Fos and actin ( 62 and $42 \mathrm{kDa}$, respectively) for the mPFC and insular cortex. B, Densitometric analysis showing the average ratio of c-Fos to actin in the EXT ( $n=12)$ and NO-EXT ( $n=12)$ groups for the mPFC (left) and insular cortex (right). EXT rats showed significantly more c-Fos expression than N0-EXT controls only in the mPFC ( $\left.{ }^{*} p<0.05\right)$, confirming the immunocytochemical findings.

2000), have no effect on extinction of contextual fear (Morgan et al., 1993), suggesting different circuits for extinction of tone versus context.

Previous studies in rats have implicated the mPFC in memory for fear extinction: (1) rats with lesions of the ventral mPFC extinguish normally but cannot recall extinction $24 \mathrm{hr}$ later (Quirk et al., 2000); (2) recall of extinction is inversely correlated with single-unit tone responses in the mPFC (Milad and Quirk, 2002), evoked potentials in the mPFC (Herry and Garcia, 2002), and glucose utilization in the mPFC (Barrett et al., 2003); and (3) stimulation of the mPFC mimicking extinction-induced tone responses reduces conditioned fear (Milad and Quirk, 2002; Milad et al., 2004). The above findings suggest that the mPFC is necessary for expression of extinction. They do not, however, tell us whether the mPFC stores a memory for extinction or is simply necessary for expression of extinction stored in other cortical or subcortical sites. The high recovery of freezing, coupled with the lack of savings, strongly suggests that the MPFC is a storage site for extinction memory. It is important to note, however, that rats with lesions of the ventral mPFC exhibit savings in the rate of reextinction in this task (Quirk et al., 2000; Lebron et al., 2003). The apparent disagreement between lesion and ANISO experiments could be attributable to spread of ANISO to additional dorsal subregions of the mPFC (Barrett et al., 2003), or partial recovery of function in lesioned animals.

Infusions of ANISO into the insular cortex had no effect, despite previous observations that this same manipulation prevents extinction of conditioned taste aversion (Berman and Dudai, 2001; Eisenberg et al., 2003). This is consistent with the established role of the insular cortex in acquisition of conditioned taste aversion (Dudai, 2002). Thus, the structure mediating the acquisition of a task may also mediate its extinction (Myers and Davis, 2002). In support of this idea for fear conditioning, infusion of NMDA antagonists (Falls et al., 1992) or MAP kinase inhibitors (Lu et al., 2001) into the BLA prevented across-day extinction of fear-potentiated startle, and microinfusions of ANISO into the amygdala prevented recall of extinction at a $30 \mathrm{~min}$ test (Lin et al., 2003). This raises the possibility that extinction requires plasticity in both the mPFC and the amygdala. A similar idea has been proposed for conditioned taste aversion, in which both the amygdala and insular cortex are required for long-term extinction memory (Bahar et al., 2003). Our findings support the hypothesis that fear extinction is initially learned in the amygdala and then transferred to cortical areas during consolidation (Santini et al., 2001; Milad and Quirk, 2002; Lin et al., 2003), similar to other forms of learning (McGaugh, 2000; Wittenberg and Tsien, 2002; Roozendaal et al., 2004).

Extinction-induced c-Fos in the mPFC suggests that ANISO prevented the expression of c-Fos-regulated genes necessary for long-term extinction memory in the mPFC. Antisense or transgenic approaches (Morrow et al., 1999; Fleischmann et al., 2003) will be needed to determine whether c-Fos expression is critical for extinction memory. Consistent with this possibility, c-Fos antisense administered intraventricularly prevented extinction of conditioned taste aversion (Swank et al., 1996). We observed increased c-Fos in all three subregions of the MPFC examined. Recording and lesion studies have focused on the role of the ventral mPFC (infralimbic area) in recall of extinction. Our findings suggest that other areas of the MPFC may also store extinction, consistent with a recent metabolic mapping study showing activation of the anterior cingulate and dorsolateral mPFC during recall of fear extinction (Barrett et al., 2003). Additional experiments will be needed to determine whether extinction signaling in the dorsal mPFC is as important as the ventral mPFC for extinction behavior.

Prefrontal dysfunction has been observed in post-traumatic stress disorder (Bremner et al., 1999; Shin et al., 2004), depression (Botteron et al., 2002), and schizophrenia (Knable and Weinberger, 1997), all of which are associated with increased fear and anxiety. It has been suggested that extinction of fear may be compromised in these disorders (Charney, 2004). Interestingly, longterm treatment with anti-psychotic medications in rats increased the levels of c-Fos in the mPFC (Kontkanen et al., 2002), suggesting that these drugs may stimulate an endogenous fear-reduction system. A better understanding of molecular mechanisms of fear extinction could lead to new pharmacological treatments for anxiety disorders targeting the $\mathrm{mPFC}$.

\section{References}

Bahar A, Samuel A, Hazvi S, Dudai Y (2003) The amygdalar circuit that acquires taste aversion memory differs from the circuit that extinguishes it. Eur J Neurosci 17:1527-1530.

Barrett D, Shumake J, Jones D, Gonzalez-Lima F (2003) Metabolic mapping of mouse brain activity after extinction of a conditioned emotional response. J Neurosci 23:5740-5749.

Berman DE, Dudai Y (2001) Memory extinction, learning anew, and learning the new: dissociations in the molecular machinery of learning in cortex. Science 291:2417-2419.

Best JD, Maywood ES, Smith KL, Hastings MH (1999) Rapid resetting of the mammalian circadian clock. J Neurosci 19:828-835.

Blanchard DC, Blanchard RJ (1972) Innate and conditioned reactions to threat in rats with amygdaloid lesions. J Comp Physiol Psychol 81:281-290.

Botteron KN, Raichle ME, Drevets WC, Heath AC, Todd RD (2002) Volumetric reduction in left subgenual prefrontal cortex in early onset depression. Biol Psychiatry 51:342-344.

Bouton ME, King DA (1983) Contextual control of the extinction of conditioned fear: tests for the associative value of the context. J Exp Psychol Anim Behav Process 9:248-265.

Bouton ME, Kenney FA, Rosengard C (1990) State-dependent fear extinction with two benzodiazepine tranquilizers. Behav Neurosci 104:44-55.

Bremner JD, Staib LH, Kaloupek D, Southwick SM, Soufer R, Charney DS (1999) Neural correlates of exposure to traumatic pictures and sound in Vietnam combat veterans with and without posttraumatic stress disorder: a positron emission tomography study. Biol Psychiatry 45:806-816. 
Charney DS (2004) Psychobiological mechanisms of resilience and vulnerability: implications for successful adaptation to extreme stress. Am J Psychiatry 161:195-216.

Debiec J, LeDoux JE, Nader K (2002) Cellular and systems reconsolidation in the hippocampus. Neuron 36:527-538.

Dudai Y (2002) Molecular bases of long-term memories: a question of persistence. Curr Opin Neurobiol 12:211-216.

Eisenberg M, Kobilo T, Berman DE, Dudai Y (2003) Stability of retrieved memory: inverse correlation with trace dominance. Science 301:1102-1104.

Falls WA, Miserendino MJ, Davis M (1992) Extinction of fear-potentiated startle: blockade by infusion of an NMDA antagonist into the amygdala. J Neurosci 12:854-863.

Fischer A, Sananbenesi F, Schrick C, Spiess J, Radulovic J (2004) Distinct roles of hippocampal de novo protein synthesis and actin rearrangement in extinction of contextual fear. J Neurosci 24:1962-1966.

Fleischmann A, Hvalby O, Jensen V, Strekalova T, Zacher C, Layer LE, Kvello A, Reschke M, Spanagel R, Sprengel R, Wagner EF, Gass P (2003) Impaired long-term memory and NR2A-type NMDA receptor-dependent synaptic plasticity in mice lacking c-Fos in the CNS. J Neurosci 23:9116-9122.

Ge H, Chiesa R, Pena DO (2003) Hzf-3 expression in the amygdala after establishment of conditioned taste aversion. Neuroscience 120:1-4.

Gewirtz JC, Falls WA, Davis M (1997) Normal conditioned inhibition and extinction of freezing and fear-potentiated startle following electrolytic lesions of medical prefrontal cortex in rats. Behav Neurosci 111:712-726.

Hall J, Thomas KL, Everitt BJ (2001) Fear memory retrieval induces CREB phosphorylation and Fos expression within the amygdala. Eur J Neurosci 13:1453-1458.

Herry C, Garcia R (2002) Prefrontal cortex long-term potentiation, but not long-term depression, is associated with the maintenance of extinction of learned fear in mice. J Neurosci 22:577-583.

Kaczmarek L (2002) c-Fos in learning: beyond the mapping of neuronal activity. In: Handbook of chemical neuroanatomy: immediate early genes and inducible transcription factors in mapping of the central nervous system function and dysfunction (Kaczmarek L, Robertson HA, eds), pp 189-215. Amsterdam: Elsevier.

Kandel ER (2001) The molecular biology of memory storage: a dialog between genes and synapses. Biosci Rep 21:565-611.

Knable MB, Weinberger DR (1997) Dopamine, the prefrontal cortex and schizophrenia. J Psychopharmacol 11:123-131.

Kontkanen O, Lakso M, Wong G, Castren E (2002) Chronic antipsychotic drug treatment induces long-lasting expression of fos and jun family genes and activator protein 1 complex in the rat prefrontal cortex. Neuropsychopharmacology 27:152-162.

Lamprecht R, LeDoux J (2004) Structural plasticity and memory. Nat Rev Neurosci 5:45-54.

Lattal KM, Abel T (2001) Different requirements for protein synthesis in acquisition and extinction of spatial preferences and context-evoked fear. J Neurosci 21:5773-5780.

Lebron K, Milad MR, Quirk GJ (2003) Rats with lesions of the ventromedial prefrontal cortex can eventually recall extinction, with additional training. Soc Neurosci Abstr 29:199.5.

Lin CH, Yeh SH, Lu HY, Gean PW (2003) The similarities and diversities of signal pathways leading to consolidation of conditioning and consolidation of extinction of fear memory. J Neurosci 23:8310-8317.

Lu KT, Walker DL, Davis M (2001) Mitogen-activated protein kinase cascade in the basolateral nucleus of amygdala is involved in extinction of fear-potentiated startle. J Neurosci 21:RC162(1-5).

Maren S, Ferrario CR, Corcoran KA, Desmond TJ, Frey KA (2003) Protein synthesis in the amygdala, but not the auditory thalamus, is required for consolidation of Pavlovian fear conditioning in rats. Eur J Neurosci 18:3080-3088.

McGaugh JL (2000) Memory-a century of consolidation. Science 287:248-251.

Milad MR, Quirk GJ (2002) Neurons in medial prefrontal cortex signal memory for fear extinction. Nature 420:70-74.

Milad MR, Vidal-Gonzalez I, Quirk GJ (2004) Electrical stimulation of medial prefrontal cortex reduces conditioned fear in a temporally specific manner. Behav Neurosci 118:389-395.
Morgan MA, Romanski LM, LeDoux JE (1993) Extinction of emotional learning: contribution of medial prefrontal cortex. Neurosci Lett 163:109-113.

Morrow BA, Elsworth JD, Inglis FM, Roth RH (1999) An antisense oligonucleotide reverses the footshock-induced expression of fos in the rat medial prefrontal cortex and the subsequent expression of conditioned fear-induced immobility. J Neurosci 19:5666-5673.

Myers KM, Davis M (2002) Behavioral and neural analysis of extinction. Neuron 36:567-584.

Nader K, Schafe GE, Le Doux JE (2000) Fear memories require protein synthesis in the amygdala for reconsolidation after retrieval. Nature 406:722-726.

Patterson TA, Rose SP, Bradley PM (1989) Anisomycin and amnesia in the chick: state-dependent effects are not present with intracranial injections. Brain Res Dev Brain Res 49:173-178.

Paxinos G, Watson C (1998) The rat brain in stereotaxic coordinates. San Diego: Academic.

Pedreira ME, Maldonado H (2003) Protein synthesis subserves reconsolidation or extinction depending on reminder duration. Neuron 38:863-869.

Pena de Ortiz S, Arshavsky Y (2001) DNA recombination as a possible mechanism in declarative memory: a hypothesis. J Neurosci Res 63:72-81.

Quirk GJ (2002) Memory for extinction of conditioned fear is long-lasting and persists following spontaneous recovery. Learn Mem 9:402-407.

Quirk GJ, Russo GK, Barron JL, Lebron K (2000) The role of ventromedial prefrontal cortex in the recovery of extinguished fear. J Neurosci 20:6225-6231.

Rescorla RA (2001) Retraining of extinguished Pavlovian stimuli. J Exp Psychol Anim Behav Process 27:115-124.

Ressler KJ, Paschall G, Zhou XL, Davis M (2002) Regulation of synaptic plasticity genes during consolidation of fear conditioning. J Neurosci 22:7892-7902.

Roozendaal B, McReynolds JR, McGaugh JL (2004) The basolateral amygdala interacts with the medial prefrontal cortex in regulating glucocorticoid effects on working memory impairment. J Neurosci 24:1385-1392.

Rosen JB, Fanselow MS, Young SL, Sitcoske M, Maren S (1998) Immediateearly gene expression in the amygdala following footshock stress and contextual fear conditioning. Brain Res 796:132-142.

Santini E, Muller RU, Quirk GJ (2001) Consolidation of extinction learning involves transfer from NMDA-independent to NMDA-dependent memory. J Neurosci 21:9009-9017.

Santini E, Burgos-Robles A, Quirk GJ (2003) Protein synthesis in the medial prefrontal cortex is required for consolidation of extinction memory. Soc Neurosci Abstr 29:199.4

Schafe GE, LeDoux JE (2000) Memory consolidation of auditory pavlovian fear conditioning requires protein synthesis and protein kinase $\mathrm{A}$ in the amygdala. J Neurosci 20:RC96(1-5).

Schafe GE, Nadel NV, Sullivan GM, Harris A, LeDoux JE (1999) Memory consolidation for contextual and auditory fear conditioning is dependent on protein synthesis, PKA, and MAP kinase. Learn Mem 6:97-110.

Shin LM, Orr SP, Carson MA, Rauch SL, Macklin ML, Lasko NB, Peters PM, Metzger LJ, Dougherty DD, Cannistraro PA, Alpert NM, Fischman AJ, Pitman RK (2004) Regional cerebral blood flow in the amygdala and medial prefrontal cortex during traumatic imagery in male and female Vietnam veterans with PTSD. Arch Gen Psychiatry 61:168-176.

Silva AJ, Kogan JH, Frankland PW, Kida S (1998) CREB and memory. Annu Rev Neurosci 21:127-148.

Swank MW, Ellis AE, Cochran BN (1996) c-Fos antisense blocks acquisition and extinction of conditioned taste aversion in mice. NeuroReport 7:1866-1870.

Vianna MR, Szapiro G, McGaugh JL, Medina JH, Izquierdo I (2001) Retrieval of memory for fear-motivated training initiates extinction requiring protein synthesis in the rat hippocampus. Proc Natl Acad Sci USA 98:12251-12254.

Vianna MR, Igaz LM, Coitinho AS, Medina JH, Izquierdo I (2003) Memory extinction requires gene expression in rat hippocampus. Neurobiol Learn Mem 79:199-203.

Wittenberg G, Tsien J (2002) An emerging molecular and cellular framework for memory processing by the hippocampus. Trends Neurosci 25: 501-505. 